\title{
Labor Market Search, Sticky Prices, and Interest Rate Policies
}

\author{
Carl E. Walsh* \\ This draft: March 2005
}

\begin{abstract}
What accounts for the significant real effects of monetary policy shocks? And what accounts for the persistent and hump shaped responses of output and inflation in response to such shocks? These questions are investigated in a model that incorporates labor market search, habit persistence, sticky prices, and policy inertia. While habit persistence and price stickiness are important for the hump shaped output response and the long, drawn out inflation response, respectively, labor market frictions increase the output response and reduce the inflation response relative to an otherwise similar model based on a Walrasian labor market. Significantly, policy inertia itself is found to be the most important factor in accounting for the magnitude of the output effects of policy shocks in the model.
\end{abstract}

JEL: E52, E58, J64

${ }^{*}$ Department of Economics, University of California, Santa Cruz, CA 95064, walshc@ucsc.edu. I would like to thank the two referees, seminar participants at UC Davis, UC Santa Barbara, the University of Hawaii, the University of British Columbia, and the Swiss National Bank for helpful comments on earlier versions of this and related research. 


\section{Introduction}

What accounts for the significant real effects of monetary policy shocks? And what accounts for the persistent and hump shaped responses of output and inflation in response to such shocks? In recent years, monetary economists have increasingly employed dynamic stochastic general equilibrium (DSGE) models based on monopolistic competition and nominal rigidities to study the impacts of monetary policy. The work of Yun (1996), Rotemberg and Woodford (1997), Goodfriend and King (1997), McCallum and Nelson (1999), and others helped to popularize this "new Keynesian" approach. However, the first generation of these models proved unable to generate the persistent output and inflation responses to shocks that are displayed in the data. This was true of the response of inflation to monetary policy shocks (Nelson 1998), as well as the response of real output (Estrella and Fuhrer 2002). In addition, the degree of price stickiness obtained in estimated new Keynesian Phillips curves is much higher than suggested by micro data on price adjustment (Galí and Gertler 1999, Sbordone 2002, Bils and Klenow 2002).

In response to these shortcomings, numerous extensions designed to generate more persistence have been explored. These extensions include structural inflation inertia, habit persistence, variable capital utilization, and sticky wages (e.g., Christiano, Eichenbaum, and Evans 2001). Less attention has been paid to the role of monetary policy itself in producing the persistence responses of output and inflation seen in the data. For example, forward-looking models of consumption imply that both current and expected future interest rates matter for current spending decisions, implying that the real output effects of transitory interest rate shocks are likely to be much smaller than the effects of shocks that generate persistent interest rate movements.

To investigate the role played by monetary policy in accounting for macroeconomic dynamics, I employ a general equilibrium model that incorporates several potential sources of persistence arising from both private agent behavior and from monetary policy. In addition to including sticky prices, habit persistence, and policy inertia, the labor market in the model is characterized by search frictions. Each of these aspects contribute to equilibrium dynamics. Sticky prices allow the monetary authority to affect the real rate 
of interest; habit persistence leads to a gradual adjustment of consumption to real interest rate changes, and the specification of the labor market means it takes time for firms to fill vacancies and for unemployed workers to find jobs. Fluctuations in total hours in the model occur through changes in the number of workers employed rather than in the number of hours per worker. This reduces the elasticity of marginal cost with respect to output, dampening the inflation effects of changes in output. After showing that the benchmark calibrated version of the model can generate the type of hump shaped, persistent responses to monetary policy shocks observed in the data, I investigate how the model's dynamics are affected by altering the degree of policy inertia, the degree of nominal price stickiness, and the degree of habit persistence in consumption.

By employing a model of labor market search, the approach of this paper contrasts with other recent work that has combined sticky prices with labor market rigidities in the form of sticky nominal wages (e.g., Christiano, Eichenbaum, and Evans 2001). As Goodfriend and King (2001, p. 4) argue that "The labor market is characterized by long-term relationships where there is opportunity and reason for firms and workers to neutralize the allocative effects of temporarily sticky nominal wages." To date, however, relatively little work has been done to study the implications of these long-term relationships between firms and workers in models with nominal rigidities.

This neglect is perhaps surprising, because the specification of the labor market has been shown to be important for the ability of real business cycle models to match important macro data. Merz (1995), Andolfatto (1996), Cooley and Quadrini (1999), den Haan, Ramey and Watson (2000), and Hairault (2002) have developed models based on the equilibrium unemployment framework of Mortensen and Pissarides (1994), while Alexopoulos $(2002,2004)$ has introduced efficiency wage considerations. These authors have all focused on either non-monetary or flexible-price equilibria. Recently, a number of authors have incorporated labor market search or efficiency wages into models that also include sticky prices. Examples include Chéron and Langot (2000), Walsh (2003), and Trigari (2004) who employ aggregate matching functions and Danthine and Kurmann (2003), who develop an efficiency wage model. While these authors conclude that 
labor market rigidities can improve the ability to match output dynamics, the models of Alexopoulos (2002) with flexible prices and Walsh (2003) and Danthine and Kurman (2003) with sticky prices imply that the inflation rate jumps immediately in response to a money supply shock with the peak impact occuring immediately, a reaction that is not consistent with the delayed and and persistent inflation response to monetary policy seen in the data. Trigari (2004), in a model that is closest in specification to the one developed in this paper, does find a more plausible inflation response, but, in common with all of this previous work, she does not explore the role of monetary policy itself in accounting for the model's dynamics.

One reason the role of systematic policy in these models has not been fully investigated is that, with the exception of Trigari (2004), previous work focusing on labor search or efficiency wage considerations in monetary models has represented policy by an exogenous process for the nominal quantity of money. However, for most of the post-war period in the U.S., the Federal Reserve has focused on interest rates, letting the money stock evolve endogenously. While the simply money demand equations implied by standard monetary general equilibrium models typically link money and interest rates in a manner that would seem to allow one to choose either a money rule or an interest rate rule, there are important advantages to working directly with an interest rate rule. First, the well-known failure of empirical money demand equations argues against employing a representation of policy that requires that money demand be specified correctly. Second, if shocks to the money stock primarily reflect non-policy disturbances, impulse response functions generated by money shocks may not provide accurate representations of a policy shock. Third, recent work has emphasized the importance of the systematic part of policy to the economy's dynamic behavior and the role of inertia as reflected in interest rate rules (Clarida, Galí, and Gertler 2000, Woodford 2003). By representing monetary policy in terms of an interest rate rule, the effects of the policy rule on equilibrium dynamics can be studied directly. ${ }^{1}$

The remainder of the paper is organized as follows. The model is developed in section

\footnotetext{
${ }^{1}$ Trigari (2004), in a similar model developed independently, also incorporates an interest rate rule. However, her main focus is on estimating the model and she does not investigate the effects of the policy rule on model dynamics.
} 
2. Calibration is discussed in section 3 . In section 4, the dynamic adjustment of output to nominal interest rate shocks is examined, while the dynamics of inflation are studied in section 5. The sources of the responses of output and inflation to a policy shock are investigated, and results for the model with labor market search are compared to those from a new Keynesian model based on a Walrasian labor market. Conclusions are summarized in section 6 .

\section{The model economy}

The model consists of households, firms, and a monetary authority. Goods are produced in a competitive wholesale sector, where production requires that a firm and a worker be matched. Wholesale firms sell their output to retail firms, of which there are a continuum of mass one. Retail firms sell differentiated goods to households, and the retail sector is characterized by monopolistic competition and price stickiness. ${ }^{2}$

The labor market aspects of the model are similar to that employed in Walsh (2003), but several modifications to policy, price setting, household behavior are introduced. ${ }^{3}$ First, I replace the assumption of an exogenous money growth rate rule with an interest rate rule. Second, to allow for multiple sources of persistence, I adopt the inflation adjustment specification of Christiano, Eichenbaum, and Evans (2001), which introduces structural inflation inertia, and I incorporate habit persistence in the preferences of the representative household. These last two modifications have been shown to improve the performance of standard new Keynesian models (Christiano, Eichenbaum, and Evans 2001, Fuhrer 2000). The resulting model is convenient for assessing the relative roles of nominal price stickiness, habit persistence, labor market search, and policy inertia on the dynamics of output and inflation. ${ }^{4}$

\footnotetext{
${ }^{2}$ Separating the goods market into a flexible price wholesale sector and a sticky price retail sector follows the approach of Bernanke, Gertler, and Gilchrist (1999).

${ }^{3}$ Further details on the model are available in an earlier version of this paper, posted at http://econ.ucsc.edu/faculty/ walshc/.

${ }^{4}$ The model differs from that of Walsh (2003) in some other, more minor ways. For example, the present paper motivates money demand from a money-in-the-utility function specification. In Walsh (2003), a cash-in-advance specification was used that led to a cost channel for monetary policy in which the nominal interest rate had a direct impact on inflation. Since this channel is somewhat controversial and is not present in most new Keynesian models, I have adopted a specification here in which it does not appear.
} 


\subsection{Households}

The representative household purchases consumption goods, holds money, and supplies one unit of labor inelasticly. Thus, the focus is on the extensive employment margin and not, as is more typical, on the intensive hours margin. ${ }^{5}$ Since some workers will be matched, while others will not be, distributional issues arise. To avoid these issues, I assume households pool consumption. ${ }^{6}$ Households are also the owners of all firms in the economy.

In models with sticky prices, output responds to demand shifts; if consumption is purely forward looking and there is no investment, consumption and output jump immediately in response to interest rate shocks. To match the hump shaped response of output seen in the data, habit persistence has become a standard component of new Keynesian models (Fuhrer 2000, Christiano, Eichenbaum, and Evans 2001). To incorporate habit persistence, preferences of the representative household are defined over $\mathcal{C}_{t}$ and $\mathcal{C}_{t-1}$, where $\mathcal{C}_{t}$ is the sum of a market purchased composite consumption good $C_{t}$ and home produced consumption $C_{t}^{h}$. The latter is defined as $C_{t}^{h}=\left(1-\chi_{t}\right) b-\chi_{t} l$, where $\chi_{t}$ is an indicator variable, equal to 1 if the household is employed and 0 otherwise. Thus, $l$ measures the consumption value of the disutility of work, and $b$ measures nontradeable home production when unemployed. Households maximize

$$
\mathrm{E}_{t} \sum_{i=0}^{\infty} \beta^{i}\left[\frac{\left(\mathcal{C}_{t+i}-h \mathcal{C}_{t+i-1}\right)^{1-\sigma}}{1-\sigma}+\phi\left(m_{t+i}\right)\right]
$$

where $\sigma>0$ is the coefficient of relative risk aversion, $h>0$ is a measure of the degree of habit persistence in consumption, and $\phi\left(m_{t}\right)$ is the utility from the household's holdings of real money balances. ${ }^{7} C_{t}$ is a Dixit-Stiglitz composite good consisting of the differentiated

\footnotetext{
${ }^{5}$ In a labor search model that allows for adjustment at both the extensive and intensive margins, Trigari (2004) finds that most adjustment occurs at the extensive margin.

${ }^{6}$ This assumption is common; see Merz (1995), Andolfatto (1996), den Haan, Ramey, and Watson (2000), Cooley and Quadrini (1999), and Hairault (2002).

${ }^{7}$ Because monetary policy is represented by an interest rate rule, $\phi(m)$ plays no role except to determine the nominal stock of money. Since the focus here is not on the stock of money, it will not be necessary to specify its functional form.
} 
products produced by retail firms and is defined as

$$
C_{t}=\left[\int_{0}^{1} c_{j t}^{\frac{\theta-1}{\theta}} d j\right]^{\frac{\theta}{\theta-1}} \quad \theta>0 .
$$

Given prices $p_{j t}$ for the final goods, this preference specification implies the household's demand for good $j$ is

$$
c_{j t}=\left(\frac{p_{j t}}{P_{t}}\right)^{-\theta} C_{t}
$$

where the aggregate retail price index $P_{t}$ is defined as

$$
P_{t}=\left[\int_{0}^{1} p_{j t}^{1-\theta} d j\right]^{\frac{1}{1-\theta}}
$$

The household's budget constraint is given by

$$
P_{t} Y_{t}+M_{t-1}^{h}+T_{t}+\left(1+i_{t-1}\right) B_{t-1}-P_{t} C_{t}-M_{t}^{h}-B_{t} \geq 0
$$

where $Y_{t}$ is the household's real income, consisting of wage income and firm profits, $M_{t}^{h}$ $\left(B_{t}\right)$ is the household's nominal holdings of money (bonds), and $T_{t}$ is a lump-sum transfer received from the government. In the aggregate, this transfer is equal to $M_{t}-M_{t-1}$, where $M$ (without the superscript $h$ ) is the aggregate nominal money stock. Bonds pay a nominal rate of interest of $i_{t}$.

The representative household's first order conditions imply the following must hold in equilibrium:

$$
\lambda_{t}=\beta\left(1+i_{t}\right) \mathrm{E}_{t}\left(\frac{P_{t}}{P_{t+1}}\right) \lambda_{t+1}
$$

where $\lambda_{t}$ denotes the total marginal utility of consumption at time $t$ and is given by

$$
\lambda_{t} \equiv\left(\mathcal{C}_{t}-h \mathcal{C}_{t-1}\right)^{-\sigma}-\beta h\left(\mathrm{E}_{t} \mathcal{C}_{t+1}-h \mathcal{C}_{t}\right)^{-\sigma}
$$




\subsection{The labor and goods markets}

The production and the labor market specifications are based on den Haan, Ramey, and Watson (2000) . Their focus is on the role of aggregate productivity shocks in a non-monetary economy, and, in order to simplify the model, I ignore the capital stock dynamics that they include.

The wholesale sector At the beginning of the period, there are $N_{t}$ matched workers and firms and $U_{t}=1-N_{t}$ unmatched workers. Existing matches face an exogenous probability $0 \leq \rho^{x}<1$ of terminating. For the $\left(1-\rho^{x}\right) N_{t}$ matches that survive, the worker and firm jointly observe the current realization of productivity and decide whether to continue the match. If the match continues, production occurs, with output equal to

$$
y_{i t}=a_{i t} z_{t}
$$

where $a_{i t}$ is a match-specific productivity disturbance and $z_{t}$ is a common, aggregate productivity disturbance. The means of both productivity disturbances are equal to 1 and both are bounded below by zero. Wholesale firms sell their output in a competitive market at the price $P_{t}^{w}$. The real value of the firm's output, expressed in terms of time $t$ consumption goods, is $P_{t}^{w} a_{i t} z_{t} / P_{t}=a_{i t} z_{t} / \mu_{t}$, where $\mu_{t}=P_{t} / P_{t}^{w}$ is the markup of retail over wholesale prices.

Firms seeking workers incur a cost in posting a vacancy and workers seeking jobs engage in a search process that takes time. Thus, existing matches can earn an economic surplus, and both the firm and the worker will wish to maintain a match with a positive expected surplus. This surplus is equal to $s_{i t} \equiv\left(a_{i t} z_{t} / \mu_{t}\right)-l+q_{t}$, where $q_{t}$ is the difference between the expected present value of a match that continues into period $t+1$ and the alternative opportunities available to the firm and the worker. Matches endogenously separate if the firm specific productivity shock is less than a critical value $\tilde{a}_{t}$, where $\tilde{a}_{t}$ is defined as the value of $a_{i t}$ at which the surplus is zero:

$$
\left(\frac{\tilde{a}_{t} z_{t}}{\mu_{t}}\right)-l+q_{t}=0
$$


If $F$ is the cumulative distribution function of $a_{i t}$, then the probability the match endogenously terminates is $F\left(\tilde{a}_{t}\right) .{ }^{8}$ A higher realization of the aggregate productivity shock $z_{t}$ directly increases the production of all matched worker/firms (see equation 5). A higher realization of $z_{t}$ will also, ceteris paribus, lower $\tilde{a}_{t}$, making it more likely that existing matches produce. This effect on $\tilde{a}_{t}$ amplifies the impact of the aggregate productivity shock on output, an effect emphasized by den Haan, Ramey, and Watson (2000). A rise in the markup of retail over wholesale prices reduces the profitability of wholesale production and increases $\tilde{a}_{t}$. These results are only partial equilibrium effects, however, since changes in aggregate productivity also affect the continuation value of a match. If an unmatched worker's opportunity utility is $w^{u}$ and an unmatched firm receives zero, the difference between the expected value to the firm and worker of a match and the worker's alternative is

$$
q_{t}=\beta \mathrm{E}_{t}\left(\frac{\lambda_{t+1}}{\lambda_{t}}\right)\left[\int_{\tilde{a}_{t+1}}^{\bar{a}}\left(1-\rho^{x}\right) s_{i t+1} f\left(a_{i}\right) d a_{i}+w_{t+1}^{u}\right]-w_{t}^{u} .
$$

Assume the worker receives a fixed share $\eta$ of the joint surplus $s_{i t}$. If an unmatched worker in period $t$ succeeds in making a match that produces in period $t+1$, she receives her opportunity utility $w_{t+1}^{u}$ plus $\eta s_{i t+1}$. The probability of this occurring is $k_{t}^{w}\left(1-\rho_{t}\right)$, where $k_{t}^{w}$ is the period $t$ probability an unmatched worker finds a job and $1-\rho_{t} \equiv$ $\left(1-\rho^{x}\right)\left(1-F\left(\tilde{a}_{t+1}\right)\right.$ is the probability that the match actually produces in period $t+1$. A worker who either fails to make a match or makes a match that fails to survive to produce in $t+1$ receives $w_{t+1}^{u}$. Thus,

$$
w_{t}^{u}=b+\beta \mathrm{E}_{t}\left(\frac{\lambda_{t+1}}{\lambda_{t}}\right)\left[k_{t}^{w}\left(1-\rho^{x}\right) \int_{\tilde{a}_{t+1}}^{\bar{a}} \eta s_{i t+1} f\left(a_{i}\right) d a_{i}+w_{t+1}^{u}\right] .
$$

Unmatched firms can post vacancies at a cost of $\gamma$ per period. If an unmatched firm does post a vacancy and succeeds in making a match that produces in period $t+1$, it receives $(1-\eta) s_{t+1}$. Free entry ensures that the expected value of a vacancy equals the

\footnotetext{
${ }^{8}$ If $l-q_{t}<0$, matches would never endogenously end since the supports of $a$ and $z$ are strictly positive. When $l-q_{t}>0$, matches do endogenously breakup.
} 
job posting cost $\gamma$. If $k_{t}^{f}$ is the probability of filling a vacancy,

$$
k_{t}^{f}\left(1-\rho^{x}\right) \beta \mathrm{E}_{t}\left(\frac{\lambda_{t+1}}{\lambda_{t}}\right)\left[\int_{\tilde{a}_{t+1}}^{\bar{a}}(1-\eta) s_{i t+1} f\left(a_{i}\right) d a_{i}\right]=\gamma
$$

A total of $\rho_{t} N_{t}$ matches dissolve prior to engaging in production. If the worker is not part of an existing match, or if her current match ends, she travels to the labor matching market. A total of

$$
u_{t} \equiv U_{t}+\rho_{t} N_{t}=1-\left(1-\rho_{t}\right) N_{t}
$$

workers will be searching for a new match. Based on an aggregate matching function, a fraction of these job-seeking workers and firms posting vacancies establish new matches. These, plus the worker-firm matches that produced during the period, constitute the stock of matches that enter period $t+1$ :

$$
N_{t+1}=\left(1-\rho_{t}\right) N_{t}+m\left(u_{t}, V_{t}\right)
$$

where $m\left(u_{t}, V_{t}\right)$ is the aggregate matching function and $V_{t}$ is the number of posted vacancies. The matching function is taken to be Cobb-Douglas with constant returns to scale ${ }^{9}$

$$
m\left(u_{t}, V_{t}\right)=\psi u_{t}^{\alpha} V_{t}^{1-\alpha}, \quad 0<\alpha<1 .
$$

The probability an unemployed worker makes a match, $k_{t}^{w}$, is

$$
k_{t}^{w}=\frac{m\left(u_{t}, V_{t}\right)}{u_{t}}=\psi\left(\frac{V_{t}}{u_{t}}\right)^{1-\alpha}
$$

Similarly, the probability a firm with a posted vacancy finds a match, $k_{t}^{f}$, is

$$
k_{t}^{f}=\frac{m\left(u_{t}, V_{t}\right)}{V_{t}}=\psi\left(\frac{V_{t}}{u_{t}}\right)^{-\alpha}
$$

Matches that endogenously end do so because they had a nonpositive surplus. This is not true, however, of matches that experience exogenous separations. Following den

\footnotetext{
${ }^{9}$ Constant returns to scale is consistent with the empirical evidence; see Petrongolo and Pissarides (2001).
} 
Haan, et. al., assume that firms experiencing exogenous separation immediately post the vacancy that is created, since these vacancies have a positive expected surplus. Of these, a fraction $k_{t}^{f}$ will be successfully filled. Thus, each period $k_{t}^{f} \rho^{x} N_{t}$ of the new jobs represent turnover at firms that experienced exogenous separations. Davis et al. (1996) define job creation as net employment gains, so in terms of the present model, this corresponds to total new matches net of turnover, $k^{f} V_{t}-k_{t}^{f} \rho^{x} N_{t}$. Hence, the job creation rate is

$$
j c r_{t}=k_{t}^{f}\left(\frac{V_{t}}{N_{t}}\right)-k_{t}^{f} \rho^{x}
$$

Similarly, job destruction is total separations net of turnover, or $\rho_{t} N_{t}-k^{f} \rho^{x} N_{t}$. The job destruction rate is

$$
j d r_{t}=\rho_{t}-k_{t}^{f} \rho^{x}
$$

Note that the percentage change in employment is $\left(N_{t+1}-N_{t}\right) / N_{t}=j c r_{t}-j d r_{t}=$ $k_{t}^{f}\left(V_{t} / N_{t}\right)-\rho_{t}$. These definitions match those of den Haan, et al. (2000).

The retail section Firms in the retail sector purchase output from wholesale producers at the price $P_{t}^{w}$ and sell directly to households. For simplicity, assume retail firms have no other inputs or costs. Each retail firm's nominal marginal cost is just $P_{t}^{w}$, and real marginal cost is equal to the inverse of the markup $\mu_{t}$. Given the structure of demand facing each retail firm (see equation 2), all retail firms would charge the same price in a flexible price equilibrium, and the retail price would be a constant markup $\theta /(\theta-1)$ over wholesale prices.

To capture nominal price stickiness, I adopt the variant of the Calvo specification employed by Christiano, Eichenbaum, and Evans (2001). Price setting decisions are made prior to observing current period shocks and all firms adjust their prices each period. However, only a fraction $1-\omega$ of firms fully optimize. The remaining firms simply index their prices according to the most recent aggregate rate of inflation. Up to a first order approximation, this specification yields

$$
\pi_{t}=\frac{\beta}{1+\beta} E_{t-1} \pi_{t+1}+\frac{1}{1+\beta} \pi_{t-1}-\frac{\kappa}{1+\beta} \hat{\mu}_{t}
$$


for the aggregate rate of inflation, where $\hat{\mu}$ denotes the percent deviation of the markup around its steady-state level.

\subsection{The monetary authority}

Most central banks implement monetary policy by controlling a short-term nominal rate of interest, and empirical work has also focused on the impact of interest rate shocks as a means of identifying the role of monetary policy (Christiano, Eichenbaum, and Evans 1999). I assume, therefore, that the nominal rate of interest follows the process

$$
R_{t}=\beta^{-\left(1-\rho_{R}\right)} R_{t-1}^{\rho_{R}}\left(\frac{P_{t}}{P_{t-1}}\right)^{\phi_{\pi}\left(1-\rho_{R}\right)} e^{\phi_{t}}
$$

where $\phi_{t}$ is a serially uncorrelated, mean zero stochastic process and $\phi_{\pi}>1$. This latter restriction ensures the existence of a unique, stationary, rational expectations equilibrium in the linearized version of the model (Svensson and Woodford 2003). Given this policy rule for the nominal rate of interest, the nominal quantity of money adjusts endogenously to satisfy the demand for money.

\section{Calibration, and summary statistics}

The properties of the model are investigated by studying a linearized version of the equilibrium conditions, expressed in terms of percentage deviations around the steadystate. Five sets of parameters characterize the model - those describing 1) household preferences, 2) the aggregate matching function and the labor market, 3) the degree of price rigidity at the retail level, 4) the behavior of the nominal interest rate, and 5) the stochastic distribution of the exogenous shocks. Parameter values are chosen to be largely consistent with those standard in nonmonetary models and with estimated new Keynesian models. Table 1 summarizes the baseline values for the key parameters of the model.

Preferences Choosing the time period to correspond to a quarter, $\beta$ is set equal to 0.989. A value of 2 is chosen for $\sigma$, implying greater risk aversion that log utility. The 
elasticity of demand for the differentiated retail goods is determined by $\theta$, and this elasticity in turn determines the markup $\mu$. The steady-state markup is set equal to 1.1, corresponding to $\theta=11$. In a version of their model without variable capital utilization, Christiano, Eichenbaum, and Evans (2001) obtain an estimate of 0.78 for the habit persistence parameter $h$.

Matching and the labor market I follow den Haan, et. al. (2000) in setting the steady-state separation rate equal to 0.1. This is based on Hall's conclusion that "around 8 or 10 percent of workers separate from their employer each quarter" (Hall, 1995, p.235) and the Davis, Haltiwanger, and Schuh (1996) finding of about an 11 percent quarterly separation rate. This is higher that the 0.07 value adopted by Merz (1995), but lower than the 0.15 used by Andolfatto (1996). Given a value of 10 percent for total separations, den Haan, Ramey, and Watson use evidence on permanent job destruction to calibrate the exogenous separation probability $\rho^{x}$ as 0.068 . This implies an endogenous separation probability $F(\tilde{a})$ of 0.0343 . From this value, and the assumed distribution function for the match specific productivity shock, the steady-state value of the cut-off productivity realization $\tilde{a}$ can be derived. I assume $\tilde{a}$ is log normally distributed, serially uncorrelated, with the standard deviation chosen to match the ratio of the standard deviation of job destruction to output reported for the U.S. by Cooley and Quadrini (1999). This implies a value of 0.13 , somewhat higher than the 0.1 used by den Haan, et. al.

For the matching function (12), I set $\alpha=0.4$ based on the estimates of Blanchard and Diamond (1989). Both Cooley and Quadrini and den Haan, et. al. fix the steady-state value of the vacancy-filling probability $k^{f}$ at 0.7 . Cooley and Quadrini cite Cole and Rogerson (1999) to set the average duration of unemployment at 1.67 quarters, which implies a steady-state value of 0.6 for $k^{w}$. It is common in labor search models with a labor-leisure choice to treat unemployment and out of the labor force as equivalent (Andolfatto 1976, Hairault 2002) and set the steady-state value of $N$ equal to 0.57 , normalizing the population size to 1 Because I ignore the labor-leisure choice, I normalize the labor force size to 1 and set $N=0.94$, implying a steady-state unemployment rate of 0.06 and a value of 0.154 for $u$, the steady-state number of workers searching each period. 
These values imply a steady-state value of 0.134 for $V$. The share of a match surplus that the worker receives, $\eta$, is set equal to 0.5 . This value is fairly standard. ${ }^{10}$

Equation (9) is used to calibrate $\gamma$. The resulting value of $\gamma$ implies job posting costs are $1 \%$ of steady-state output, equal to the value used by Hairault (2002) to calibrate the cost of creating a job. Finally, the steady-state versions of (6), (7), and (8), together with previously calibrated values, residually determine $l+b .^{11}$

Price rigidity The degree of nominal rigidity is determined by $\omega$, the fraction of firms each period that do not optimally adjust their price. Empirical estimates of forwardlooking price setting models here suggest prices are fixed for extended periods of time (Galí and Gertler 1999, Sbordone 2002). For the baseline parameter values, I adopt a value for $\omega$ of 0.85 based on Galí and Gertler's estimates.

Policy The interest rate rule for monetary policy given by equation (18) is a modified Taylor rule in which the nominal rate responds to inflation but not to output. I adopt the same parameter values used by Bernanke, Gertler, and Gilchrist (1999). They argue that the long-run nominal rate response to a 100 basis point increase in inflation is about 110 basis points, implying $\phi_{\pi}=1.10$. The baseline calibration of equation (18) sets $\rho_{R}=0.9$, a value consistent with empirical evidence on the high degree of inertia displayed by central bank policy rules. ${ }^{12}$

Shocks There are two exogenous aggregate shocks in the model; the monetary policy shock and the aggregate productivity shock. The standard deviation of the policy shock $\phi_{t}$ is set to 0.002 ; this is consistent with estimated federal funds rate equations. The log aggregate productivity shock is assumed to follow an $A R(1)$ process: $\log z_{t}=\rho_{z} \log z_{t-1}+$ $\varepsilon_{t}$. I set $\rho_{z}$ equal to 0.95 while the standard deviation of $\varepsilon_{t}, \sigma_{\varepsilon}$, is set at 0.01 . This value for $\sigma_{\varepsilon}$ is chosen to provide a rough match between the model's prediction for the standard

\footnotetext{
${ }^{10}$ Cooley and Quadrini evaluate their model for much lower values of $\eta$, setting it equal to 0.1 and 0.01 . Walsh (2003) finds the dynamics to be sensitive to the choice of $\eta$.

${ }^{11}$ Only the sum $l+b$ enters the equilibrium conditions. I set $b=0$ and determine $l$ residually. Note that one could start instead with a calibrated value of $l+b$ and this would affect the steady-state value of $\tilde{a}$ and the endogenous separation rate.

${ }^{12}$ See Clarida, Galí, and Gertler (2000) for evidence on central bank policy rules.
} 
deviation of output to the standard deviation of U. S. real GDP. ${ }^{13}$

Summary statistics Table 2 presents standard deviations based on U. S. data, expressed relative to the standard deviation of output. These values are taken from den Haan, et. al. and Cooley and Quadrini and are based on quarterly H-P filtered data. Row 2 of the table shows the results from the labor search model. With the exception of the magnitude of the standard deviation of the job creation rate, the model does a good job matching the U.S. data. Job creation is too volatile in the model, but the model does predict that job destruction is more volatile than job creation. At the baseline calibration, the model implies slightly more employment and inflation volatility than observed in the data.

\section{Sources of output persistence}

Figure 1 shows the response of output, employment, and inflation to a one percentage point positive nominal interest rate shock in the model. All three variables display the hump-shaped responses that are typically associated with VAR estimates of the impact of a nominal interest rate shock on real variables (see, e.g., Christiano, Eichenbaum, and Evans 1999). Vacancies (not shown) drop immediately in reaction to the contractionary monetary policy shock. However, the number of job seekers (also not shown) follows a hump-shaped path, rising for the first year after the shock. In response to the policy shock, the job finding probability falls for workers and rises for firms that do post vacancies, reflecting the rise in the number of searching workers relative to vacancies.

These dynamic patterns reflect the net effects of labor market search, habit persistence, price stickiness, and monetary policy. Tables 3 and 4 provide some evidence on the roles each of these factors play in generating the impulse response functions shown in figure 1. The top panel of Table $3 \mathrm{~A}$ shows the effects on the output response to a policy shock of varying the degree of nominal rigidity $(\omega)$ and the inertia in the monetary policy rule $\left(\rho_{R}\right)$, holding the parameter governing habit persistence at its baseline value

\footnotetext{
${ }^{13}$ It is common to set $\sigma_{\varepsilon}=0.007$, and this is the value used by den Haan, et. al. (2000).
} 
$(h=0.78)$. Row 1 corresponds to the baseline values of $\omega=0.85$ and $\rho_{R}=0.9$. Row 2 reduces $\rho_{R}$ to 0.7 . This reduces the median lag from 5 quarters to 4 ; more significantly, it reduces the maximum impact on output from -0.43 to -0.07 , and this peak impact occurs just 2 quarters after the shock rather than 4 quarters. Returning $\rho_{R}$ to 0.9 and reducing the degree of price stickiness (row 3) reduces the median lag to 2 quarters. Reducing both parameters, $\omega$ to 0.5 and $\rho_{R}$ to 0.7 , has little further impact on the median lag but significantly reduces the total and peak impacts. Comparing across rows, it appears that policy inertia is of primary importance in determining the size of the output effect; temporary interest rate shocks have little impact.

The bottom panel of Table 3A repeats the exercise with $h=0.55$, the estimate for this parameter obtained by Trigari (2004). With less habit persistence, the same basic conclusions hold; $\rho_{R}$ is primarily responsible for the quantitative size of the output effects of an interest rate shock. Comparing the top and bottom panels of the table reveals that habit persistence significantly increases the median lag and the timing of the peak output response while reducing the size of the response.

These effects can also be seen from figures 2 and 3 , which illustrate two alternative ways of decomposing the contributions to output dynamics of habit persistence, price stickiness, and policy. In both figures, the solid line shows the output response to an interest rate shock under the baseline calibration, and the dotted line shows the response when the model is calibrated to reflect less habit persistence, more price flexibility, and less policy inertia by setting $h=0.55, \omega=0.5$, and $\rho_{R}=0.7$. From this specification, $\rho_{R}$ is increased to 0.9 . The resulting impulse response function for output is shown by the dashed line in figure 2. The primary effect of greater policy inertia is to increase significantly the output effects of the policy shock without altering the basic shape of the response. Output reaches its trough one period after the shock.

Next, $h$ is increased from 0.55 to 0.78 , with $\omega=0.5$ and $\rho_{R}=0.9$. Greater habit persistence shifts the impulse response upwards (to the dot-dashed line) and generates more of a hump-shaped pattern. Finally, the degree of nominal price stickiness is increased by setting $\omega=0.85$; this yields the solid baseline response function. Greater price 
stickiness serves to amplify the effects of the interest rate shock and delay the recovery of output.

Because the effect of each parameter on the impulse response is nonlinear, the ordering used in figure 2 is only one possibility. Figure 3 again starts with the dotted line associated with $h=0.55, \omega=0.5$, and $\rho_{R}=0.7$ and then adds back in the sources of persistence in an order opposite to the one employed in figure 2. First, $\omega$ is increased. This shifts the impulse response from the dotted line to the dashed line. The effects are small. Next, $h$ is increased, yielding the dot-dashed line. This reduces the impact on output but increases the median lag and the period of peak impact from one period after the shock to two periods after the shock. Finally, $\rho_{R}$ is increased, producing the solid response function. Policy inertia significantly increases both the magnitude of the effect and pushes the peak effect from two periods after the shock to four periods after the shock.

Thus, the model suggests that habit persistence is important for generating humpshaped output responses but not for accounting for the magnitude of the output response. Instead, policy inertia is the major cause of large real effects of interest rate shocks. Increased nominal rigidity also matters, particularly when policy is also highly inertial. ${ }^{14}$

To assess the role played by the labor market specification, Table 3B shows the effects of parameter variation on the response of output to an interest rate shock in a new Keynesian model that incorporates a Walrasian labor market. This model includes the same dynamic inflation adjustment equation, habit persistence in consumption, and policy rule as in the labor search model. With a Walrasian labor market and flexible wages, marginal cost is related to the marginal rate of substitution between leisure and consumption and the marginal product of labor. I assume utility is separable in consumption and leisure and denote the elasticity of utility with respect to work by $\zeta$. I set $\zeta=0.5$; calibration is otherwise the same as in the labor search model.

Two points are worth noting. First, for all parameter constellations shown, the median lag and the timing of the peak output response to an interest rate shock are delayed in the model incorporating labor market search relative to the basic new Keynesian model.

\footnotetext{
${ }^{14}$ Figures 2 and 3 are only two of the six different ways of assessing the effects of the three parameters $h, \omega$, and $\rho_{R}$. However, an examination of the other four possibilities (available from the author) does not alter the conclusions stated in the text.
} 
Second, as measured by total and peak effects on output, the labor market search model with $\omega=0.5$, a degree of nominal rigidity in line with survey evidence on price setting, matches the output response in a new Keynesian model with $\omega=0.85$.

\section{Sources of inflation persistence}

Turning to the inflation dynamics in the labor search model, Table 4A reports information on the impact of policy shocks on inflation for different values of nominal rigidity, policy inertia, and habit persistence. Comparing rows 1 and 2 with rows 3 and 4 reveals that the degree of price stickiness has a major impact on the median inflation lag, while a comparison of rows 1 and 3 with rows 2 and 4 shows that policy inertia is critical for determining the total and peak impacts of policy shocks on inflation. The bottom panel of the table (rows 5-8) shows that similar conclusions hold when there is less habit persistence, though habit persistence increases the lag in the impact of policy shocks on inflation.

Consistent with the evidence in Tables $3 \mathrm{~A}$ and $3 \mathrm{~B}$ showing the stronger output effects in the labor market search model versus a basic new Keynesian model, a comparison of Tables $4 \mathrm{~A}$ and $4 \mathrm{~B}$ shows that the inflation response is stronger in the new Keynesian model. Not surprisingly, both models show that it is policy inertia that produces a large total effect on inflation. The labor search model produces longer lags in the response of inflation to policy shocks for all the parameter combinations reported.

Figures 4 and 5 provide information on the aspects of the model responsible for the muted and delayed response of inflation to a policy shock that was seen in figure 1 . In both figures, the solid line shows the output response to an interest rate shock under the baseline calibration, and the dotted line shows the response when the model is calibrated to reflect less habit persistence, more price flexibility, and less policy inertia by setting $h=0.55, \omega=0.5$, and $\rho_{R}=0.7$. From the specification yielding the dotted line, $\rho_{R}$ is increased to 0.9. The resulting impulse response function is shown by the dashed line in figure 4. The primary effect of greater policy inertia is to increase significantly the inflation effects without altering the basic shape of the response. 
Next, $h$ is increased from 0.55 to 0.78 , with $\omega=0.5$ and $\rho_{R}=0.9$. Greater habit persistence shifts the impulse response upwards (to the dot-dashed line) and generates a more delayed inflation response. Finally, the degree of nominal price stickiness is increased by setting $\omega=0.85$; this yields the solid baseline response function. Greater price stickiness serves to reduce and stretch out significantly the inflation effects of the interest rate shock.

Figure 5 alters the parameters in a different order. It again starts with the dotted line associated with $h=0.55, \omega=0.5$, and $\rho_{R}=0.7$ and then increases $\omega$. This shifts the impulse response from the dotted line to the dashed line. Greater price stickiness reduces the response of inflation, and increasing habit persistence further dampens the effect (see the dot-dashed line). Notice that the scales differ in figures 4 and 5. Finally, $\rho_{R}$ is increased, producing the solid response function. Policy inertia very significantly increases the magnitude of the effect .

Thus, the model suggests that policy inertia is the major cause of large inflation effects of interest rate shocks, just as it was responsible for the large real output effects. ${ }^{15}$

As was noted in the introduction, the degree of nominal rigidity implied by estimated new Keynesian inflation adjustment equations is quite high. Based on the work of Galí and Gertler (1999) and Sbordone (2002), the baseline calibration set $\omega=0.85$, implying that only $15 \%$ of all firms adjust their price optimally each period. Bils and Klenow (2002) report, based on micro data from the consumer price index, that prices are fixed on average for six months, implying a value of $\omega=0.5$. Christiano, Eichenbaum, and Evans (2001), in a model with price and wage stickiness, obtain an estimate of $\omega$ on the order of one half. Figure 6 shows how the introduction of the labor market search process can reduce the degree of nominal rigidity needed to capture output dynamics. The lines labeled labor market search, $\omega=0.85$ and new Keynesian, $\omega=0.85$ represent the response of output to a positive nominal interest rate shock under the baseline calibrations for the two models. The line labeled labor market search, $\omega=0.5$ shows the response in the labor market search model when the degree of nominal price stickiness is significantly

\footnotetext{
${ }^{15}$ An examination of the other four possibilities of ordering the changes in $h, \omega$, and $\rho_{R}$ does not alter these basic conclusions.
} 
reduced by lowering $\omega$ to 0.5 . As the figure shows, the introduction of a search-based labor market allows the model to capture the same dynamics as in a Walrasian model with significantly less nominal rigidity.

Figure 7 shows that a similar conclusion holds for inflation. To obtain the same magnitude and persistence of inflation in response to a policy shock, the labor market search model needs much less price stickiness than the Walrasian labor market model does.

\section{Conclusions}

This paper has incorporated nominal price stickiness, habit persistence, and policy inertia into a model of labor market search to study the dynamic impact of nominal interest rate shocks. The model produces real output and inflation responses to nominal interest rate shocks that display the hump shaped pattern typically seen in estimated VARs. Labor market rigidities introduced by the process of matching job seekers with job vacancies amplify the real impact and reduce the inflation impact of a nominal interest rate shock. As a consequence, much less nominal rigidity is necessary in the labor market search model than in the corresponding new Keynesian model. While habit persistence and price stickiness affect output and inflaiton dynamics, policy inertia is shown to be the critical factor in accounting for the sizable output and inflation effects of policy shocks.

\section{References}

[1] Alexopoulos, M., "A Monetary Business Cycle Model with Unemployment," University of Toronto, January 2002.

[2] Alexopoulos, M., "Unemployment and the Business Cycle," Journal of Monetary Economics, 51(2), March 2004, 257-298.

[3] Andolfatto, D., "Business Cycles and Labor-Market Search," American Economic Review, 86 (1), March 1996, 112-132.

[4] Bernanke, B., M. Gertler, and S. Gilchrist, "The Financial Accelerator in a Quantitative Business Cycles Framework," Chapter 21 of J. Taylor and M. Woodford (eds.), The Handbook of Macroeconomics, Vol. 1C, Elsevier Science, North-Holland, 1999.

[5] Bils, M. and P. Klenow, "Some Evidence on the Importance of Sticky Prices," January 2002. 
[6] Blanchard, O. J. and P. Diamond, "The Beveridge Curve," Brookings Papers on Economic Activity, 1989, 1-60.

[7] Chéron, A. and F. Langot, 1999, "The Phillips and Beveridge Curves Revisited," Economics Letters, 1999, 69, 371-376.

[8] Christiano, L. J., M. Eichenbaum, and C. Evans, "Monetary Policy Shocks: What Have We Learned and to What End?" Chapter 2 of J. Taylor and M. Woodford (eds.), The Handbook of Macroeconomics, Vol. 1A, Elsevier Science, North-Holland, 1999.

[9] Christiano, L. J., M. Eichenbaum, and C. Evans, "Nominal Rigidities and the Dynamic Effects of a Shock to Monetary Policy," May 2001, forthcoming, Journal of Political Economy.

[10] Clarida, R., J. Galí, and M. Gertler, "Monetary Policy Rules and Macroeconomic Stability: Evidence and Some Theory," Quarterly Journal of Economics, 115(1), 2000, 147-180.

[11] Cole, H. and R. Rogerson, "Can the Mortensen-Pissarides Matching Model Match the Business Cycle Facts?" International Economic Review, 40 (4), Nov. 1999, 933959 .

[12] Cooley, T. F. and V. Quadrini, "A Neoclassical Model of the Phillips Curve Relation," Journal of Monetary Economics, 44 (2), Oct. 1999 165-193.

[13] Danthine, J. P. and A. Kurmann, "Fair Wages in a New Keynesian Model of the Business Cycle," CIRPÉE Working Paper 03-02, April 2003.

[14] Davis, S. J., J. C. Haltiwanger, and S. Schuh, Job Creation and Job Destruction, Cambridge (MA): MIT Press, 1996.

[15] den Haan, W. J., G. Ramey, and J. Watson, "Job destruction and Propagation of Shocks," American Economic Review, June 2000, 90 (3), 482-498.

[16] Estrella, A. and J. C. Fuhrer, "Dynamic Inconsistencies: Counterfactual Implications of a Class of Rational Expectations Models," American Economic Review, 92(4), Sept. 2002, 1013-1028.

[17] Fuhrer, J. C., "Habit Formation in Consumption and Its Implications for MonetaryPolicy Models," American Economic Review, June 2000, 90 (3), 367-390.

[18] Galí, Jordi and Mark Gertler, "Inflation Dynamics: A Structural Econometric Analysis," Journal of Monetary Economics, 44 (2), Oct. 1999, 195-222.

[19] Goodfriend, M. and R. G. King, "The New Neoclassical Synthesis and the Role of Monetary Policy," NBER Macroeconomic Annual 1997, Cambridge, MA: MIT Press, 231-283.

[20] Hairault, Jean-Olivier, "Labor Market Search and International Business Cycles," Review of Economic Dynamics July 2002, 5(3), 535-558.

[21] Hall, R. E., "Lost Jobs," Brookings Papers on Economic Activity, 1995:1, 221- 256. 
[22] McCallum, B. and E. Nelson, "An Optimizing IS-LM Specification for Monetary Policy and Business Cycle Analysis," Journal of Money, Credit, and Banking, 31 (3), August 1999, part 1, 296-316.

[23] Merz, M., "Search in the Labor Market and the Real Business Cycle," Journal of Monetary Economics, 36 (2), Nov. 1995, 269-300.

[24] Mortensen, D. T. and C. A. Pissarides, "Job Creation and Job Destruction in the Theory of Unemployment," Review of Economic Studies, 61 (3), July 1994, 397-416.

[25] Nelson, Edward, "Sluggish Inflation and Optimizing Models of the Business Cycle," Journal of Monetary Economics, 42 (2), October 1998, 303-322.

[26] Petrongolo, B. and C. A. Pissarides, "Looking into the Black Box: A Survey of the Matching Function," Journal of Economic Literature, 39, 2001, 390-431.

[27] Rotemberg, J. and M. Woodford, "An Optimizing-Based Econometric Model for the Evaluation of Monetary Policy," NBER Macroeconomic Annual 1997, Cambridge, MA: MIT Press, 297-346.

[28] Sbordone, A. M., "Prices and Unit Labor Costs: A New Test of Price Stickiness," Journal of Monetary Economics, 49(2), March 2002, 265-292.

[29] Svensson, L. E. O. and M. Woodford, "Implementing Optimal Policy Through Inflation-Forecast Targeting," Princeton University, Jan. 2003.

[30] Trigari, A., "Equilibrium Unemployment, Job Flows and Inflation Dynamics," European Central Bank, Working Paper Series No. 304, Feb. 2004.

[31] Walsh, C. E., "Labor Market Search and Monetary Shocks," in Elements of Dynamic Macroeconomic Analysis, S. Altuĝ, J. Chadha, and C. Nolan (eds), Cambridge: Cambridge University Press, 2003, 451-486.

[32] Woodford, M., Interest and Prices - Foundations of a Theory of Monetary Policy, Princeton: Princeton University Press, 2003.

[33] Yun, "Nominal Price Rigidity, Money Supply Endogeneity, and Business Cycles," Journal of Monetary Economics, 37 (2), April 1996, 345-370. 
Table 1

Calibrated Parameters: Baseline Values

\begin{tabular}{|c|c|c|c|c|c|}
\hline \multicolumn{6}{|c|}{ A. Preferences } \\
\hline & $\sigma$ & $\theta$ & $h$ & & \\
\hline & $0.989 \quad 2$ & 11 & 0.78 & & \\
\hline \multicolumn{6}{|c|}{ B. Labor Market } \\
\hline$\rho^{s}$ & $\rho^{x}$ & $k^{f}$ & $k^{w}$ & $N$ & $\eta$ \\
\hline 0.10 & $0.068 \quad 0.4$ & 0.7 & 0.6 & 0.94 & 0.5 \\
\hline \multicolumn{6}{|c|}{ C. Price rigidity } \\
\hline \multirow{2}{*}{\multicolumn{6}{|c|}{$\begin{array}{c}\omega \\
0.85\end{array}$}} \\
\hline & & & & & \\
\hline \multicolumn{6}{|c|}{ D. Policy } \\
\hline & $\sigma_{\phi}$ & \multirow{2}{*}{\multicolumn{2}{|c|}{$\begin{array}{c}\rho_{R} \\
0.9\end{array}$}} & \multirow{2}{*}{\multicolumn{2}{|c|}{$\begin{array}{c}\phi_{\pi} \\
1.10\end{array}$}} \\
\hline & 0.002 & & & & \\
\hline \multicolumn{6}{|c|}{ E. Productivity } \\
\hline & $\overline{\sigma_{\varepsilon}}$ & \multirow{2}{*}{\multicolumn{2}{|c|}{$\begin{array}{c}\rho_{z} \\
095\end{array}$}} & \multicolumn{2}{|l|}{$\sigma_{a}$} \\
\hline & 0.01 & & & 0.13 & \\
\hline
\end{tabular}

Table 2

Business cycle properties $\left(\sigma_{i} / \sigma_{y}\right)$

\begin{tabular}{ccc}
\hline & U.S. data & Labor Search Model \\
\hline Output & $\sigma_{Y}=1.60$ & $\sigma_{Y}=1.65$ \\
Employment & 0.62 & 0.70 \\
Job creation rate & 2.89 & 3.90 \\
Job destruction rate & 4.26 & 4.25 \\
Inflation & 0.35 & 0.43 \\
\hline
\end{tabular}


Table 3A

Effects of parameter variation on output response

\begin{tabular}{|c|c|c|c|c|c|}
\hline \multicolumn{6}{|c|}{ Labor search model } \\
\hline & & \multirow[t]{2}{*}{ Median Lag } & \multicolumn{3}{|c|}{ Impact } \\
\hline & & & Total & Max & Period $\dagger$ \\
\hline \multicolumn{6}{|c|}{$h=0.78$} \\
\hline 1. & $\omega=0.85, \rho_{R}=0.9$ & 5 & -4.39 & -0.43 & 4 \\
\hline 2. & $\omega=0.85, \rho_{R}=0.7$ & 4 & -0.55 & -0.07 & 2 \\
\hline 3. & $\omega=0.5, \rho_{R}=0.9$ & 2 & -1.91 & -0.31 & 3 \\
\hline 4. & $\omega=0.5, \rho_{R}=0.7$ & 2 & -0.41 & -0.07 & 2 \\
\hline \multicolumn{6}{|c|}{$h=0.55$} \\
\hline 5 . & $\omega=0.85, \rho_{R}=0.9$ & 2 & -5.71 & -0.73 & 2 \\
\hline 6. & $\omega=0.85, \rho_{R}=0.7$ & 1 & -0.86 & -0.17 & 1 \\
\hline 7 . & $\omega=0.5, \rho_{R}=0.9$ & 1 & -2.07 & -0.58 & 1 \\
\hline 8. & $\omega=0.5, \rho_{R}=0.7$ & 1 & -0.64 & -0.16 & 1 \\
\hline
\end{tabular}

$\dagger$ Number of periods after shock in which maximum effect occurs.

Table 3B

Effects of parameter variation on output response

\begin{tabular}{lccccc}
\hline \multicolumn{5}{c}{ New Keynesian model } \\
\hline \multicolumn{5}{c}{ Lags } & Impact \\
\hline & $h=0.78$ & & & & \\
Median & Total & Max & Period $\dagger$ \\
1. & $\omega=0.85, \rho_{R}=0.9$ & 1 & -1.17 & -0.27 & 2 \\
2. & $\omega=0.85, \rho_{R}=0.7$ & 1 & -0.23 & -0.06 & 2 \\
3. & $\omega=0.5, \rho_{R}=0.9$ & 0 & -0.37 & -0.14 & 0 \\
4. & $\omega=0.5, \rho_{R}=0.7$ & 0 & -0.09 & -0.04 & 0 \\
\hline \multicolumn{6}{c}{$h=0.55$} \\
5. & $\omega=0.85, \rho_{R}=0.9$ & 1 & -2.12 & -0.57 & 1 \\
6. & $\omega=0.85, \rho_{R}=0.7$ & 0 & -0.47 & -0.15 & 1 \\
7. & $\omega=0.5, \rho_{R}=0.9$ & 0 & -0.79 & -0.35 & 0 \\
8. & $\omega=0.5, \rho_{R}=0.7$ & 0 & -0.22 & -0.10 & 0 \\
\hline
\end{tabular}

$\dagger$ Number of periods after shock in which maximum effect occurs. 
Table 4A

Effects of parameter variation on inflation response

\begin{tabular}{|c|c|c|c|c|c|}
\hline \multicolumn{6}{|c|}{ Labor search model } \\
\hline & & \multirow[t]{2}{*}{ Median Lag } & \multicolumn{3}{|c|}{ Impact } \\
\hline & & & Total & Max & Period $\dagger$ \\
\hline \multicolumn{6}{|c|}{$h=0.78$} \\
\hline 1. & $\omega=0.85, \rho_{R}=0.9$ & 10 & -3.88 & -0.24 & 9 \\
\hline 2. & $\omega=0.85, \rho_{R}=0.7$ & 11 & -0.25 & -0.02 & 9 \\
\hline 3. & $\omega=0.5, \rho_{R}=0.9$ & 5 & -5.74 & -0.67 & 5 \\
\hline 4. & $\omega=0.5, \rho_{R}=0.7$ & 7 & -0.58 & -0.06 & 7 \\
\hline \multicolumn{6}{|c|}{$h=0.55$} \\
\hline 5 . & $\omega=0.85, \rho_{R}=0.9$ & 9 & -4.08 & -0.27 & 8 \\
\hline 6. & $\omega=0.85, \rho_{R}=0.7$ & 8 & -0.28 & -0.02 & 6 \\
\hline 7 . & $\omega=0.5, \rho_{R}=0.9$ & 3 & -6.04 & -0.93 & 4 \\
\hline 8. & $\omega=0.5, \rho_{R}=0.7$ & 3 & -0.77 & -011 & 4 \\
\hline
\end{tabular}

$\dagger$ Number of periods after shock in which maximum effect occurs.

Table $4 \mathrm{~b}$

Effects of parameter variation on inflation response

\begin{tabular}{|c|c|c|c|c|c|}
\hline \multicolumn{6}{|c|}{ New Keynesian model } \\
\hline & & Median Lag & & Impact & \\
\hline & & & Total & $\operatorname{Max}$ & Period $\dagger$ \\
\hline \multicolumn{6}{|c|}{$h=0.78$} \\
\hline 1. & $\omega=0.85, \rho_{R}=0.9$ & 4 & -6.20 & -0.87 & 5 \\
\hline & $\omega=0.85, \rho_{R}=0.7$ & 5 & -1.07 & -0.13 & 5 \\
\hline 3. & $\omega=0.5, \rho_{R}=0.9$ & 2 & -7.57 & -2.13 & 3 \\
\hline 4. & $\omega=0.5, \rho_{R}=0.7$ & 2 & -1.74 & -0.46 & 2 \\
\hline \multicolumn{6}{|c|}{$h=0.55$} \\
\hline & $\omega=0.85, \rho_{R}=0.9$ & 3 & -6.40 & -1.06 & 4 \\
\hline & $\omega=0.85, \rho_{R}=0.7$ & 3 & -1.14 & -0.18 & 3 \\
\hline & $\omega=0.5, \rho_{R}=0.9$ & 1 & -7.77 & -2.90 & 2 \\
\hline & $\omega=0.5, \rho_{R}=0.7$ & 1 & -1.87 & -0.68 & 2 \\
\hline
\end{tabular}

$\dagger$ Number of periods after shock in which maximum effect occurs. 


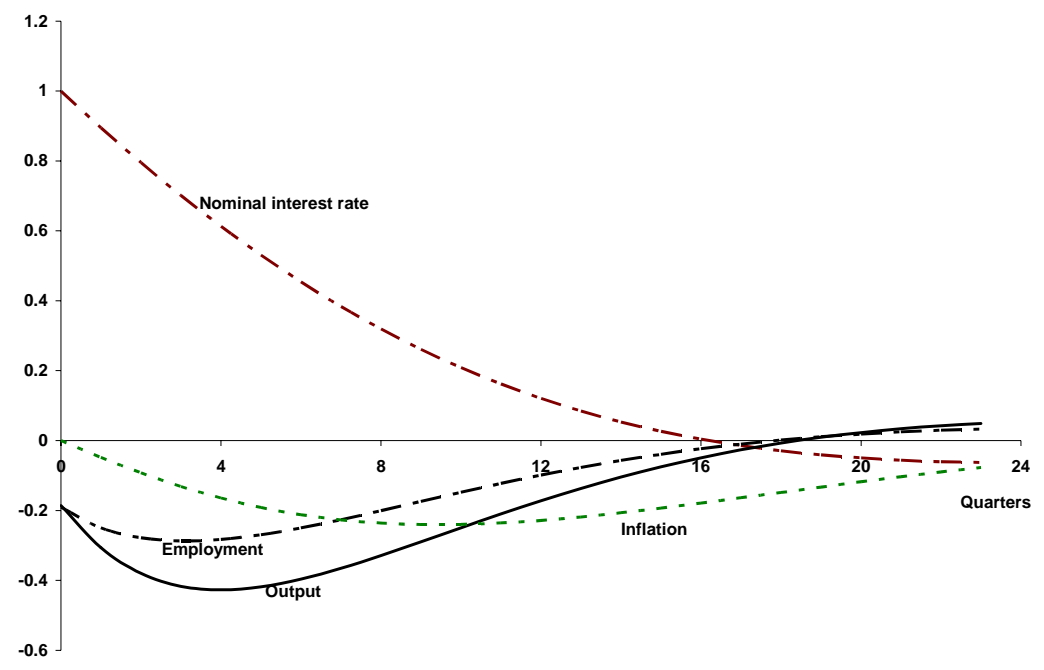

Figure 1: Impulse response in labor market search model (baseline calibration)

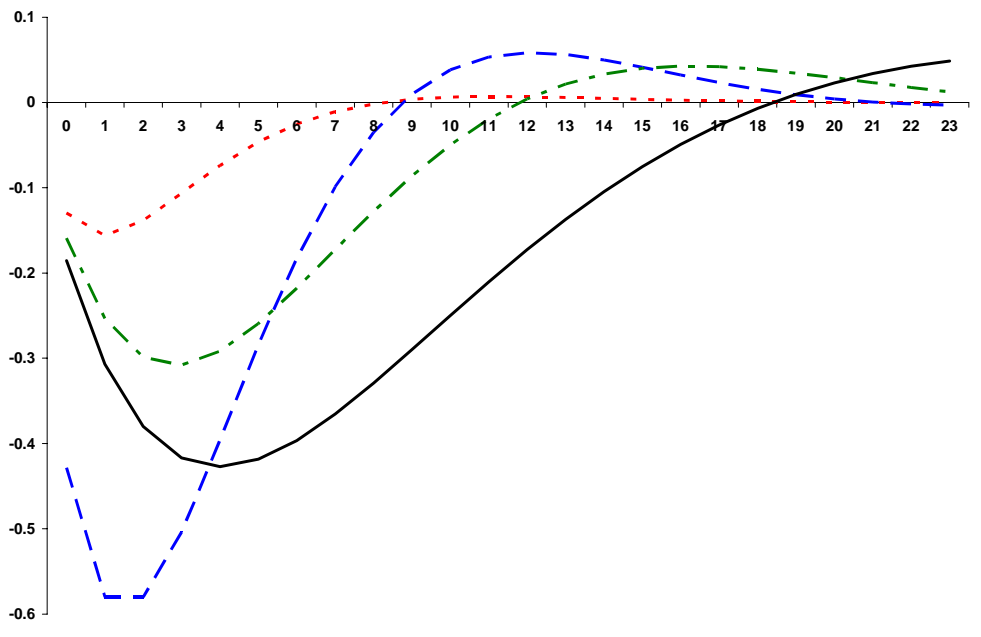

Figure 2: The dotted line shows the response of output to a policy shock with $h=0.55$, $\omega=0.5$, and $\rho_{R}=0.7$. The dashed line shows the effect of increasing $\rho_{R}$ To 0.9 . Increasing $h$ to 0.78 yields the dot-dashed line, while increasing $\omega$ to 0.85 (to yield the baseline calibration of $h=0.78, \omega=0.85$, and $\rho_{R}=0.9$ ) produces the impulse response shown as a solid line. 


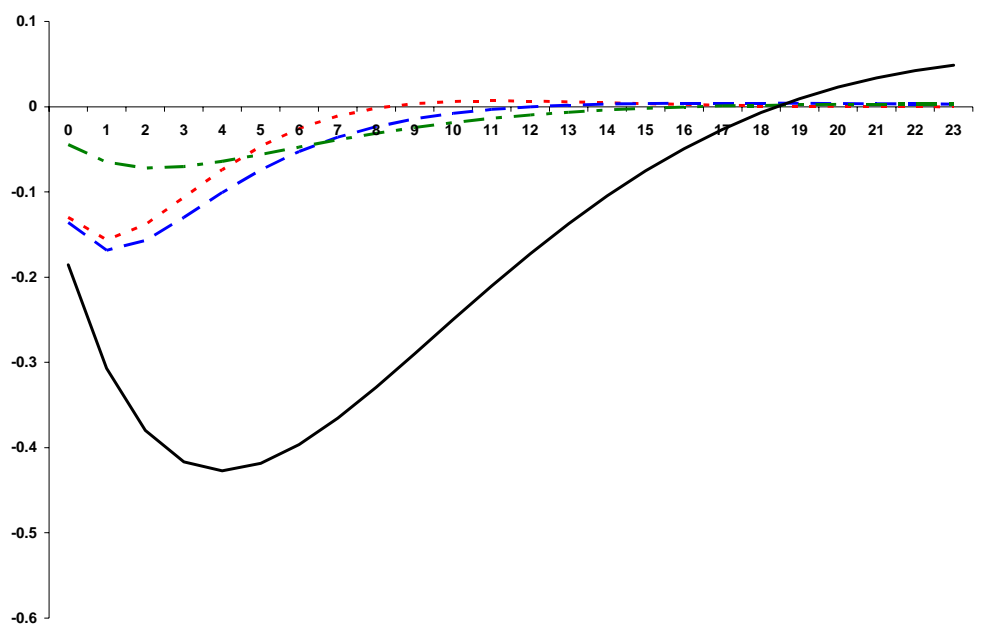

Figure 3: The dotted line shows the response of output to a policy shock with $h=0.55$, $\omega=0.5$, and $\rho_{R}=0.7$. The dashed line shows the effect of increasing $\omega$ To 0.85 . Increasing $h$ to 0.78 yields the dot-dashed line, while increasing $\rho_{R}$ to 0.9 (to yield the baseline calibration of $h=0.78, \omega=0.85$, and $\left.\rho_{R}=0.9\right)$ produces the impulse response shown as a solid line.

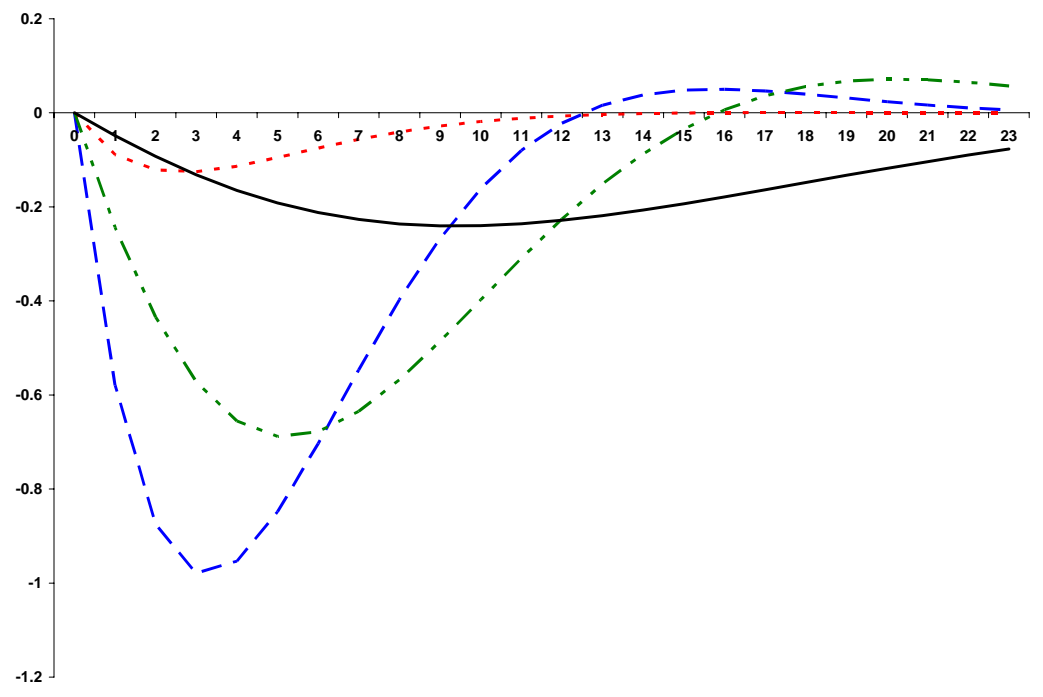

Figure 4: The dotted line shows the response of inflation to a policy shock with $h=0.43$, $\omega=0.5$, and $\rho_{R}=0.7$. The dashed line shows the effect of increasing $\rho_{R}$ To 0.9 . Increasing $h$ to 0.78 yields the dot-dashed line, while increasing $\omega$ to 0.85 (to yield the baseline calibration of $h=0.78, \omega=0.85$, and $\rho_{R}=0.9$ ) produces the impulse response shown as a solid line. 


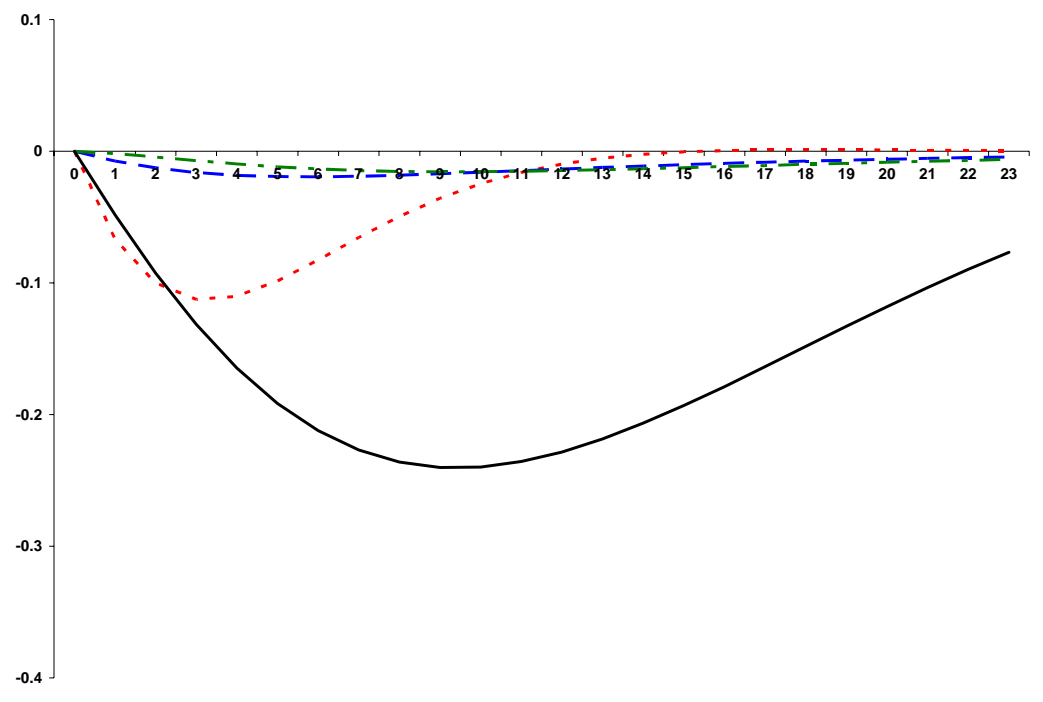

Figure 5: The dotted line shows the response of inflation to a policy shock with $h=0.55$, $\omega=0.5$, and $\rho_{R}=0.7$. The dashed line shows the effect of increasing $\omega$ To 0.85 . Increasing $h$ to 0.78 yields the dot-dashed line, while increasing $\rho_{R}$ to 0.9 produces the impulse response shown as a solid line. Note scale differs from that in figure 4.

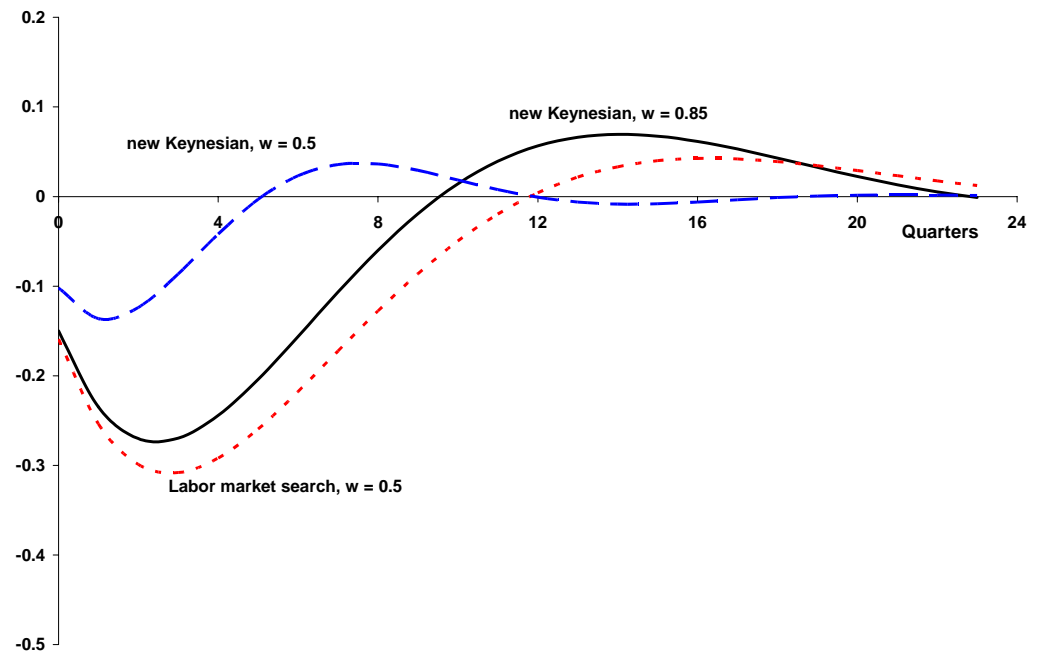

Figure 6: Output response to policy shock 


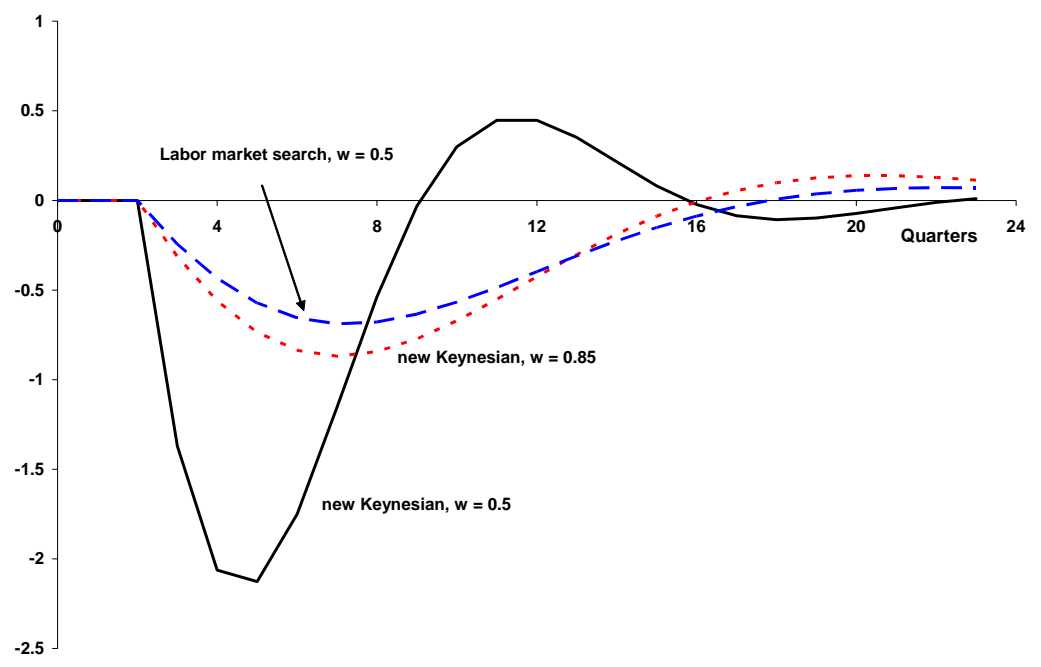

Figure 7: Inflation response to a policy shock 